\title{
Simulations as an Assessment Tool for the Feasibility of Logistics Innovations Motivated by the Emergence of Supply Chain Risk
}

\author{
Dávid Strnad ${ }^{1}$, Gabriel Fedorko $^{1 *}$, Vieroslav Molnár ${ }^{2}$, Pavol Fialek ${ }^{1}$ \\ 1 Technical University of Kosice, Letna 9, 04200 Kosice, Slovak Republic \\ 2 Faculty of Manufacturing Technologies, Technical University of Košice with a seat in Prešov, Bayerova 1, 08001 \\ Prešov, Slovak Republic \\ * Corresponding author's email: gabriel.fedorko@tuke.sk
}

\begin{abstract}
In carrying out manufacturing processes, an important role is played by the supply chain. Proper functioning of the supply chain is affected by several factors, the parameters and manifestation of which may change under situations of crises. However, disruptions may not solely pose a threat to supply chains that should be avoided. In some cases, the presence of risk may have a positive side to it, namely being the motivating factor initiating innovation. This may result in improvement of the status quo, increase in productivity and creating ways of eliminating consequences of risk. On a concrete example, the paper shall describe how innovation, spurred by crisis brought about by the current pandemic situation, can be implemented to the supply chain in the automotive sector.
\end{abstract}

Keywords: supply chain management - SCM, supply chain links, supply chain risks, automotive, interior management.

\section{INTRODUCTION}

Supply chain management (SCM) is related to the activities in the individual links in the chain and their interconnections. The supply chain starts with sourcing, through processing in accordance with customer requirements, to distribution to the final customer using a suitable means of transport. Supply chains are adversely affected by situations of crisis [1].

The accompanying phenomenon of crisis periods is usually various risks, which in their consequences can interrupt (or reduce) completely unplanned, exceptionally completely stop the material and information flows in the supply chain. If material flows are interrupted for a short time, the outage can be overlapped, under appropriate management. A long-term outage in the supply chain results in production shutdown, which will ultimately result in non-fulfilment of final customer orders. The manner in which supply chains operate reflects the sector of industry they pertain to [2]. This means there are certain differences in how they operate in different industrial sectors [3]. One of the industrial sectors with the most sophisticated system of supply chain management is automotive.

Participating in automotive supply chains are many enterprises with the main line of business being manufacturing, and specializing in activities starting with design, through development and production, all the way to distribution and sales of particular components necessary for the final car completion. Nevertheless, automotive is not the only sector with great emphasis on the quality of supply chain operation. Thus, the research into supply chains continues to garner a great deal of attention [4].

Supply Chain Management (SCM) has been addressed by a number of authors. The description of the actions for each link in the chain is more or less different for each author. The concept of supply chain and management of material flows in individual links and between partners using Kanban loops, supply principles in JIT and JIS systems, application of TOC (theory 
of constrains), reduction of changeover time by SMED, total productive maintenance (TPM) etc. with emphasis on added value and process efficiency, describes Gros et al.[5].

From the perspective of current management, the management of supply chains is described by van der Vorst et al. [6] as an integrated planning linked to the coordination and control of all undertaken activities. The objective of supply chain management is to deliver better value-added goods to the customer while reducing their own costs.

Mentzer et al. [7] describes Supply Chain Management (SCM) from the point of view of strategic management of supply chain activities of all enterprises, which includes all material, information and financial flows, including reverse flows.

According to Gála et al. [8] supply chain management is an activity related to the integration of organizational units and the controlled cooperation of material, information and financial flows in order to increase the competitiveness of the supply chain as a whole.

Supply Chain Management according to Tarantilis et al. [9] coordinates mutual cooperation in the management of material, information and financial flows, including reverse flows. In particular, the optimization of material flows with a view to minimizing their costs is beneficial for coordinated action within the chain.

Harrison and Remko van Hoek [10] analyze the internal and external links in the supply-customer chain divided into suppliers, manufacturers and customers. Among these groups, goals, process improvements, assessments and customer benefits are defined within the SCM.

Supply Chain modelling is a matter for the organisation Supply-Chain Council, using the SCOR model. The functional SCOR model is used to determine the level of supply chain efficiency. The model works by comparing the measured parameters in the chain with the predetermined criteria. The obtained values are used to improve the processes in each supply chain links [11].

Search and communication functions of internet can be used to manage supply chains, which facilitate work related to, for example, search, evaluation and selection of new suppliers, including the provided services. The internet provides a quick and easy comparison of price offers using electronic catalogues. The internet provides a quick, simple and clear orientation for the purchase of resources, services and logistics processes [12]. Other options to be deployed to managing supply chains under critical situations are the multicriteria methods. Hittle and Leonard [13] were checking the application of this approach by analyzing several types of crises and disruptions. They concluded that the issue of supply chains should focus on proactive risk management.

Supply chain risks may arise as a result of several factors [14:16]. An example of such risks is the current pandemic situation. It has been felt in many links of the supply chain. That is the reason why it has been subjected to research. One of the latest work worth mentioning is that by Armani et al. [17].

However, a critical situation may not necessarily have only negative consequences. Its emergence may create a space for resolving the crisis through implementation of new technologies, improvement of managing principles, and for changing the entire way in which the supply chain is organized. The paper provides a scrutiny into a situation where the crisis brought about a modification of the supply chain, ultimately benefiting the functioning of the entire supply chain.

\section{SUPPLY CHAIN RISKS IN AUTOMOTIVE}

Risks in the supply chain pose a threat to unplanned interruption or restriction of material flow. Material flow interruption or restriction can occur in any link in the supply chain and usually result in production shutdown and in a threat to supply to the end customer. Tang [18] pointed out two main types of SCR:

- short-term, e.g. in case of delayed delivery,

- long-term, such as a coronavirus pandemic.

Automotive is susceptible to many a risk. The number of different types of risks that may occur in the supply chain during the crisis period (risks natural, strategic, market, production, transport, technical, etc.), are essential for the automotive industry those related to execution of the manufacturing process. These are risks mainly related to the human factor. They emerge usually due to high sickness absence. They are ever more critical especially due to the fact that a shortage of workers adversely affects all links across the supply chain. There is a natural reduction in supply, which has a knock-on effect in the supply chain. Ultimately, this requires solutions with higher operating costs - necessary overtime hours, Saturday shifts, etc. 


\section{CURRENT SITUATION IN AUTOMOTIVE}

The current global pandemic situation caused by the COVID - 19 virus has affected all industrial sectors. The car industry is very severely affected by the crisis, which depends in particular on the operation of a large number of businesses supplying the final customer, which are the car manufacturers. The epidemy has been severely felt at some links of the supply chain. To ensure production, a host of measures needed to be implemented, affecting directly or indirectly production in the automotive industry and functioning of supply chains.

As a result of the epidemiological regulations, the necessary administrative and technical measures have been taken, such as:

- measures to enter the premises,

- hand disinfection, automatic temperature measurement, mobile shelters for trucks,

- measures for the receipt of goods and in the stock management,

- protective plexiglass on the reception,

- measures in the in-house transport,

- measures in the packaging management and the distribution of goods.

At the same time, to ensure supply chain operability, a form of securing the information flow had to be adopted. Communication between workers takes place while using mobile phones, sending messages via a computer, and organizing video-conferences. Problems related to the production assurance are dealt with operationally by crisis management.

Paradoxically, the coronavirus crisis has accelerated many innovative solutions not only in logistics activities. The digitization of printed documents has been carried out in line with the accepted Industry 4.0 concept. Automation and robotics, virtual reality and other new technologies are applied continuously in production:
- in material handling (smart gloves, smart glasses, C-frame, E-frame, Schooter system, pick-byvision, pick-by-frame, pick-by-point and more),

- but also in the so-called green logistics (CNG trucks, gigaliner, EDIS internal kit using solar collectors, drones in the warehouse economy etc.).

\section{RISKS IN SUPPLY CHAIN AS A MOTIVATION FOR INNOVATION}

As already mentioned, the presence of a crisis does not manifest itself only in negative outcomes, conversely, it may be some kind of an accelerator, speeding up implementation of new technologies and procedures. Mostly these are technologies already planned to be deployed, or those getting tested, and the emergence of a critical situation literally demands they be applied. In the automotive industry, one of such areas is digitization of logistics activities.

a) Virtual reality applications for order picking (finishing) - After the pallet barcode has been read into the system, the system will light up the location of the pallet on the floor. The pallet shall be provided with a wrapping and protective sheet, on which the system displays successively the individual parts to be picked up as ordered. Not only individual parts are displayed, but also their most convenient location on the pallet. The conformity of the part to the order is checked by subtracting the barcode of each part.

b) Container utilization using artificial intelligence applications - The use of AI (Artificial Intelligence - enables technical systems to mimic human abilities) enables to make maximum use of container loading surfaces by optimally arranging the transported goods (Fig. 1).

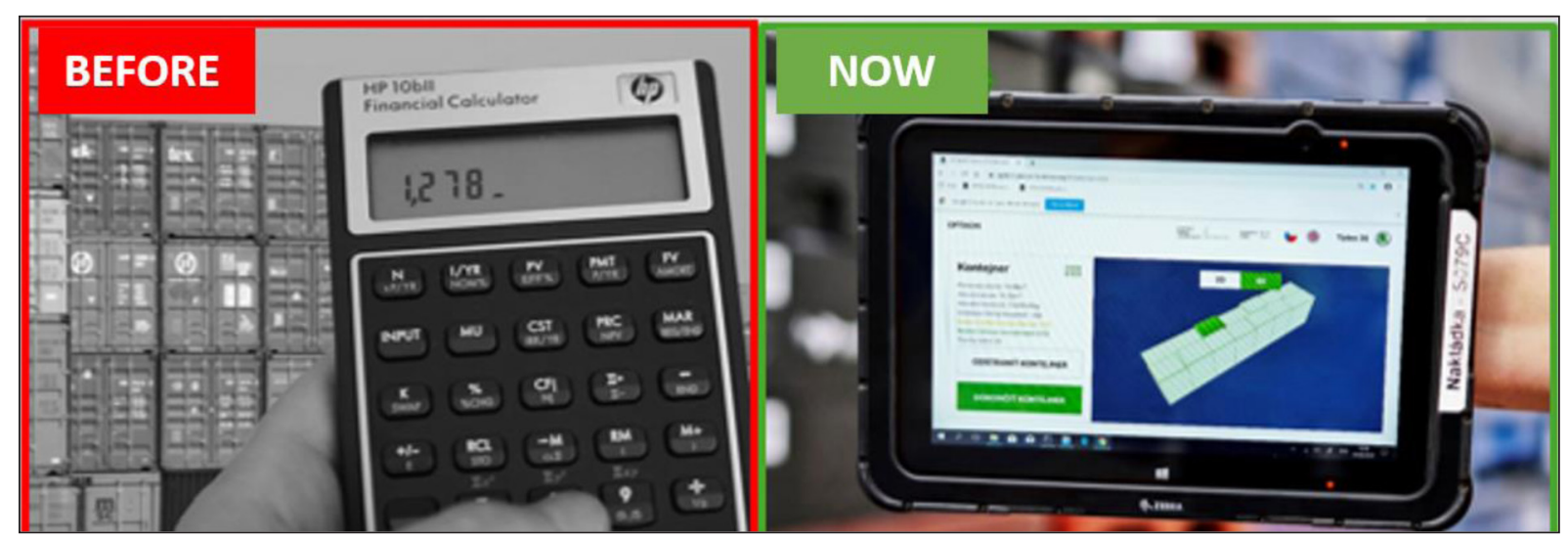

Fig. 1. AI application for container utilisation 
c) Digital on-line inventory - By digitizing the inventories carried out on a regular basis, the initial time needed to carry out the inventory was significantly reduced. E-inventory eliminated lengthy work, dramatically increased efficiency and minimized potential human error (Fig. 2).

d) Digitization of material flow - The digitization of material flow allows the system to monitor the on-line material flow both internally and externally. Material flow monitoring allows the necessary measures to be taken in a timely manner, if necessary, to ensure a smooth supply of material, thus avoiding possible interruption or cessation of production.

e) $\mathrm{CO}_{2}$ emission calculator - Meeting the Euro 6 emission standards, which are binding and continuously monitored in the EU for car manufacturers. The $\mathrm{CO}_{2}$ emission calculator allows to monitor this obligation. If the manufacturer exceeds the permitted limits, it is subject to considerable EU sanctions. The standard sets the limit valuesfor pollutantemissions frompetrol and diesel vehicles, depending onthe massof pollutant per travelled distance.

f) Mobile digital maintenance of logistics equipment - The detection and rapid removal of a defect on any logistics equipment without paperwork allows direct digital transmission to the internal information system (e.g. missing caster wheel) and thus to the maintenance site (Fig. 3).

g) Digitization of work-flows - For each operation, there are monitors with instructions that the operator activates using his/her work card. The guidelines contain only relevant information related to its current task. Using text and $3 \mathrm{D}$ views or video tutorials, the operator is informed exactly how and where to place the part/component. The assembly line application significantly reduces the time and risk of possible operator error.

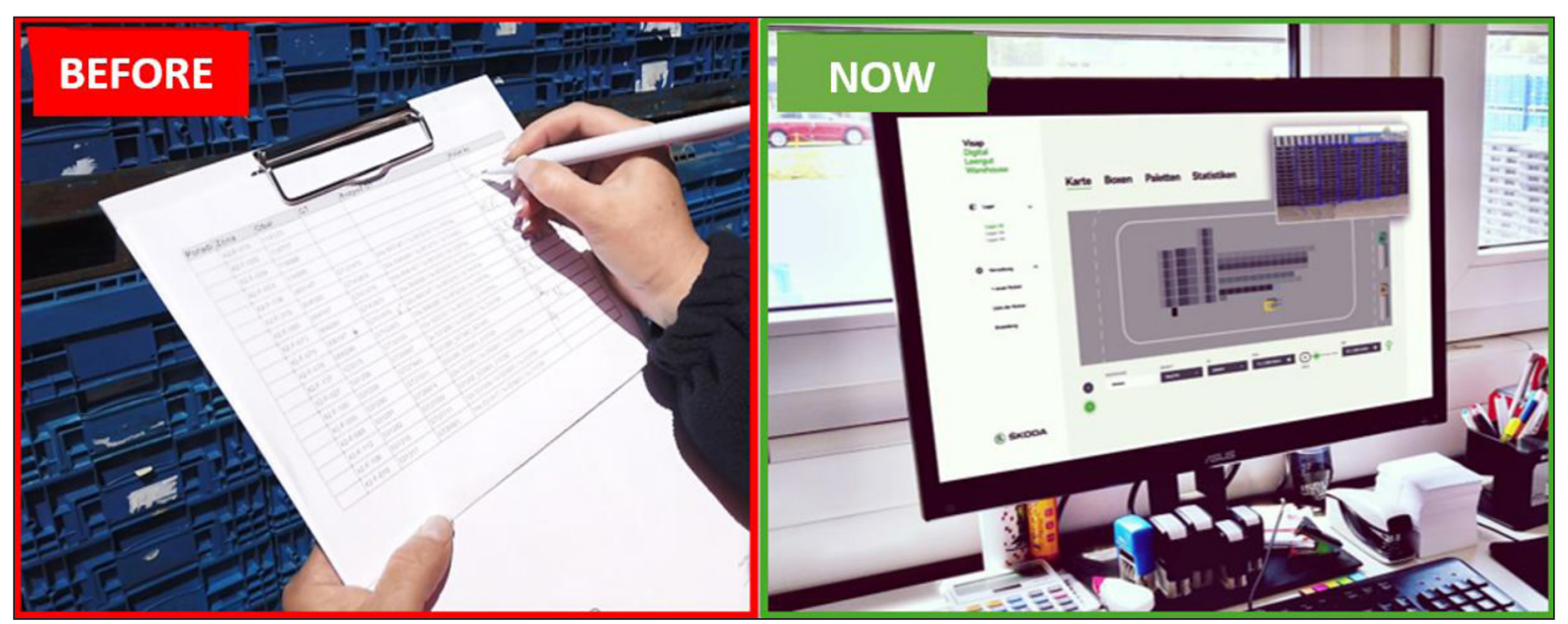

Fig. 2. Digitalized Inventory

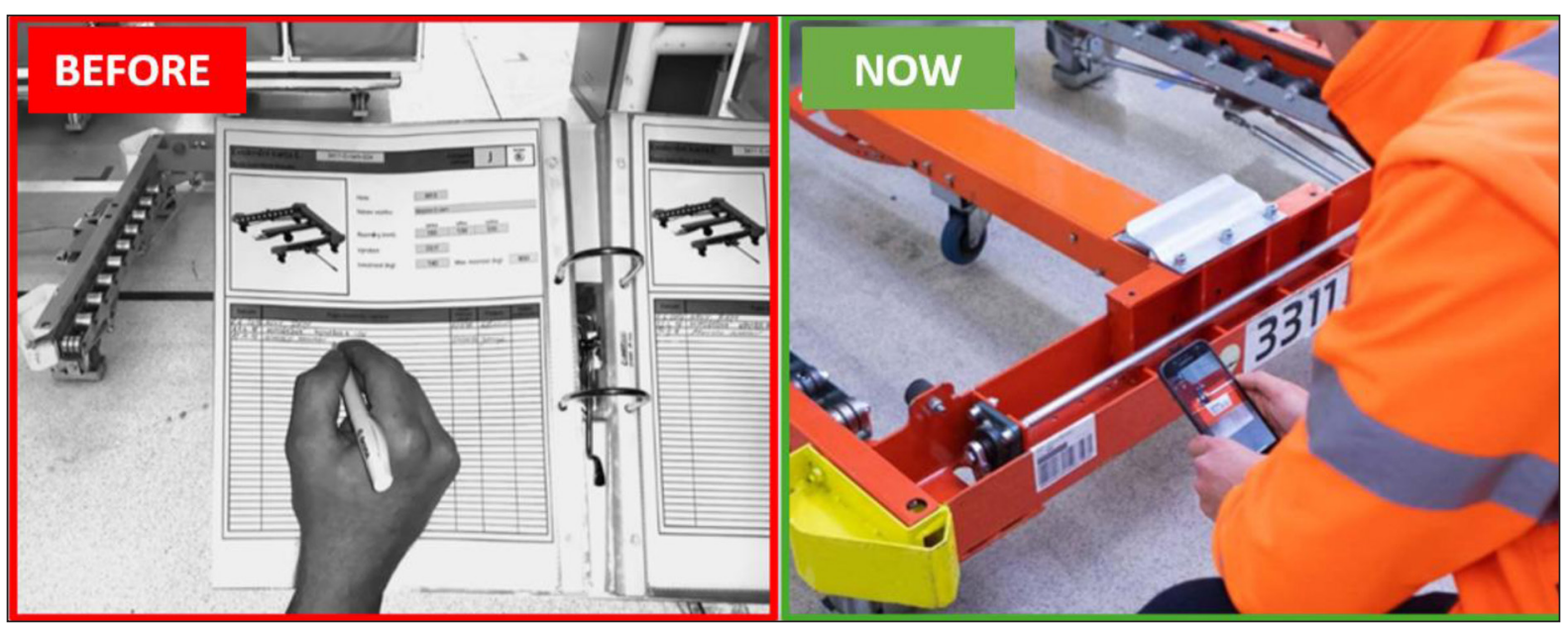

Fig. 3. Digital transmission of the fault detected 
h) Digital processing of documentation - Document digitization aimed at converting company data from originally paper to electronic form. At the same time, the digitized documentation was organized and organized according to predefined criteria. The user can easily access the necessary data, but only to a certain level that is allowed to vary according to functional classifications. The necessary data is acquired by the user in the form and structure required.

i) Digital quality management - Digital quality management replaces manual stamping after each work operation. After the operator's work card is inserted into the card reader, all data for the relevant production step is stored in the system. The output control staff shall only record the inspection performed by touching the appropriate controlled points that are on the touch screen.

\section{AUTOMATION OF LOGISTICS OPERATIONS}

Digitization is not the only process applied in automotive to supply chains as a result of their disruption. The hazard the pandemic poses to operators' health, and the need for greater hygienic safety, required yet another approach to ensure continued operation of supply chains; namely complex or partial process automation. However, implementation of process automation must meet current requirements in the automotive industry.

The current requirements in the automotive industry are given by high quality, flexibility, reliability and fair compliance with the given development cycles, including compliance with market requirements. The high quality, as well as the quantity of cars produced, place high requirements on the organization and management of production and logistics processes.

Meeting the high requirements, together with the demand for ever-increasing quantities of pieces produced, improving the efficiency of work while respecting the high quality, can be achieved through innovative activities, automation and robotics. The automotive industry is very flexible in the automation and robotics application and has always been an active and creative promoter of new technologies.

The current global pandemic situation is developing and moving this process further. The main trend in automation of the logistics operations is that of developing autonomous transport systems. These are dominated by autonomous outside and in-house vehicles.

Autonomous tractor units form a logistics train with trucks. Trucks are equipped with standard or more recent dynamic frames that carry sequential pallets. Magnetic tape stuck on the floor is commonly used to steer the tractor units. More recently, the tractor units are driven by the laser system.

The tractor units are equipped with sensors that monitor the surroundings of the route up to a distance of two meters. If necessary, the tractor unit will stop the logistics train practically on the spot. Innovative tractor unit solutions can avoid an obstacle when detected or can automatically load an empty pallet on a given signal when driving backwards.

In addition to autonomous transport systems, automation is making headway in the warehousing (Fig. 4). This fact allows increased logistics efficiency

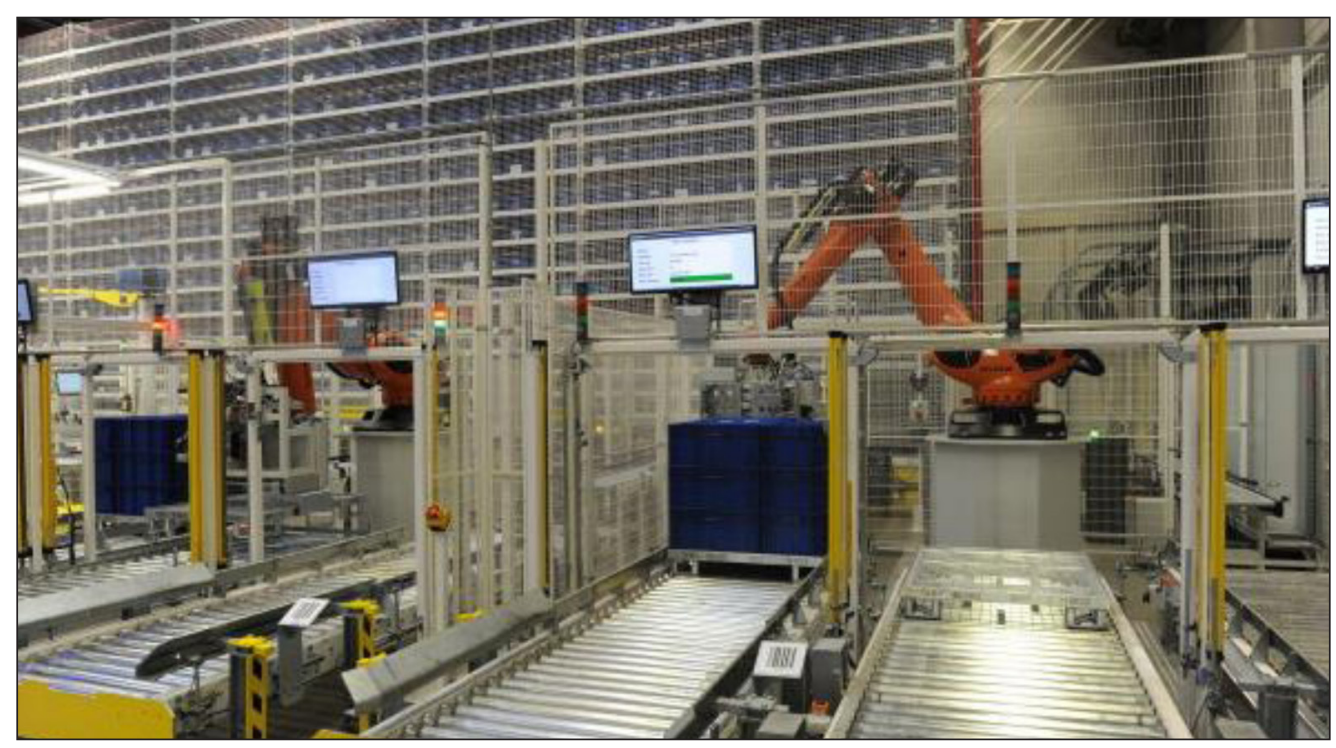

Fig. 4. Entrance part of automated small parts warehouse (AKL) with two robots 
in the storage of smaller parts due to the high degree of automation. Storing and removing parts from the assembly line according to recalls from the assembly line is fully automatic in the order in which they will be assembled, i.e. in a just-in-sequence system.

\section{UNIVERSAL SIMULATION MODEL TO SUIT THE NEEDS OF SUPPLY- CHAIN AUTOMATION}

The implementation and support of the supply-chain automation needs might be met through an approach that is based on the use of computer simulation tools. As a powerful tool, computer simulation can be used especially in the field of in-house transport.

In-house transport is the operation of handling units running between facilities on the company's premises. The disruption the supply chains have been experiencing is introducing various transport units carrying out transport processes unattended. These unmanned carts and logistics trolleys are navigated, as has been already mentioned, by the magnetic strip stretching on the floor in the production facilities of the company.

Since several transport systems operating in parallel are often used in production for the supply of workstations, this fact must be taken into account when implementing the automation of this process. For this reason, the use of a simulation model of universal architecture seems to be a suitable solution. By universality we mean the ability of the model to be adapted in the simplest way possible to a specific situation simulated. Creating a simulation model takes place in several steps.

In the first step of creating a universal model of in-house transport, it is necessary to create a system of transport routes and individual workstations, which will meet the needs of automated systems. The creation of such a network may look like the one in Figure 5.

Subsequently, the individual workstations to be served need to be connected to the transport routes. In this step, it is necessary to take into account their individual specificities and structure. This procedure can be demonstrated on the case of an assembly center.

The assembly center consists of three assembly lines. These lines are robotized and do not need to be operated by workers. The assembly lines follow each other in a sequence and form an integral part of the assembly center. If anything happens to one assembly line, the entire assembly center will not work. Each line consists of a magazine, a process station, a conveyor belt and an assembly station.

The carts are positioned to visit and deliver parts to all three lines. These lines perform various process operations required to create the product. The whole process will be fully automated.

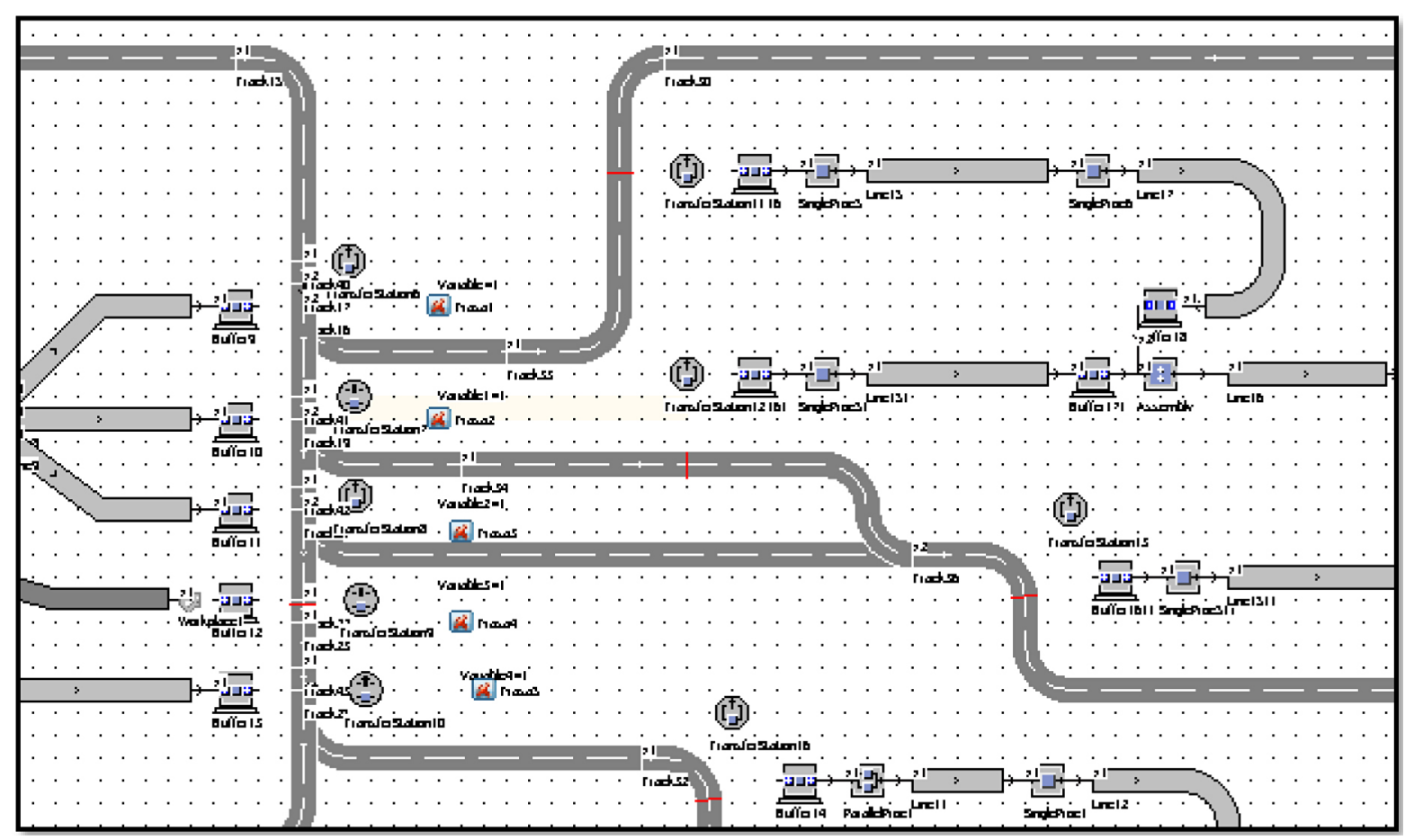

Fig. 5. Network of routes and workstations for the universal simulation model 


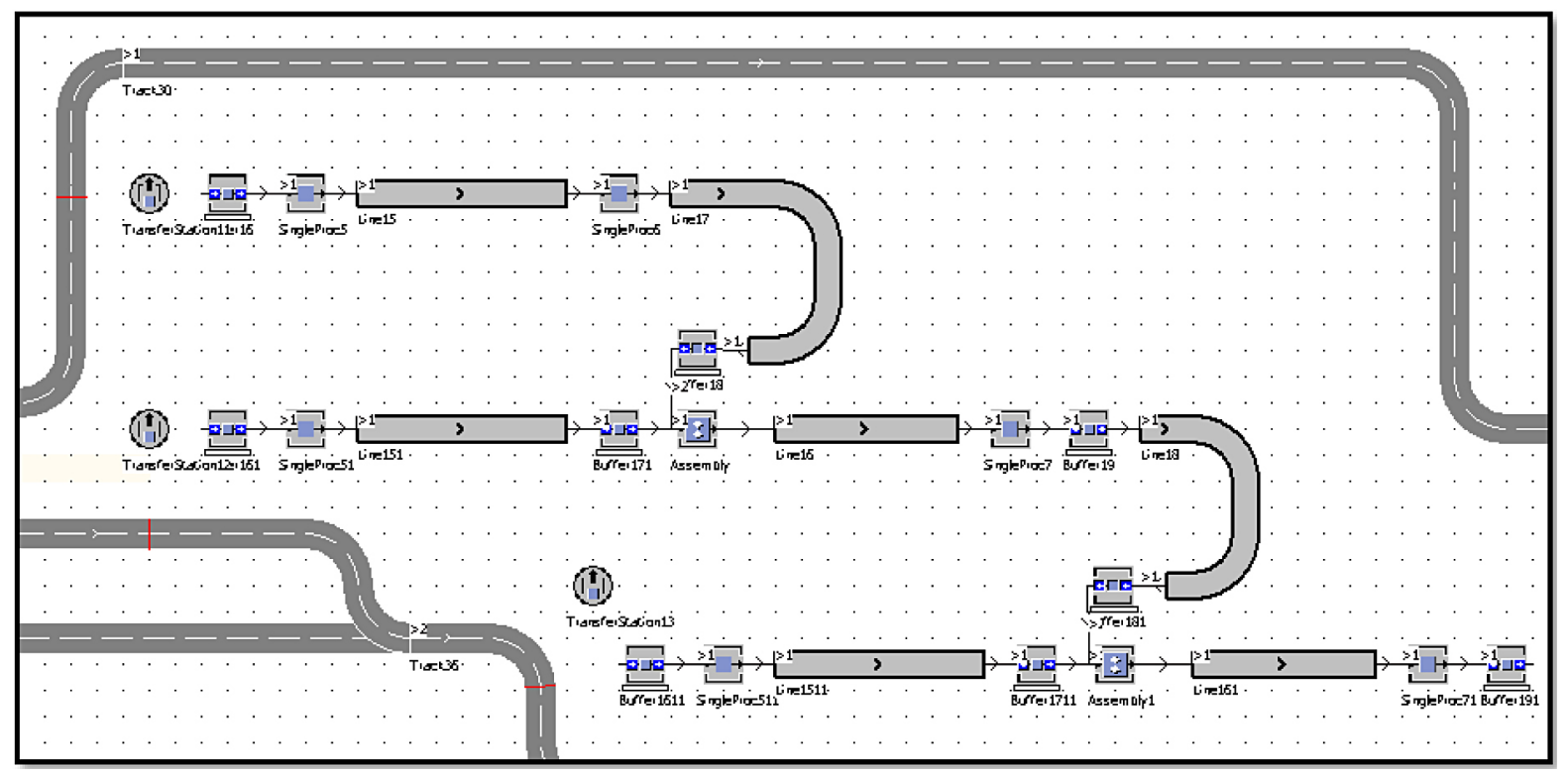

Fig. 6. Assembly center

There is also an assembly line in the model, which is separate and is not followed by any other assembly lines. This line can be used for various purposes. It can even serve as a control station. Alternatively, it can be a line that produces components similar to those of the lines in the assembly center, but it may be used for other purposes, or it may be a line with a different type of product manufacturing. This line also ends with a magazine, which stores the product for a certain time until it is removed by the appropriate means of transport.

All carts that take over a specific product from a given assembly line, from a given magazine, travel through the lower route, in the vicinity of the mentioned production operations of the model at hand. Vehicels that deliver the necessary material to the machining center are combined into the lower return route together with the carts that return from the assembly lines. According to Fig. 7, these are blue and green arrows. Button links are created in the model. The button is used to let the carts re-enter the input area of the model for loading of the given material imported from the warehouse. This means that the carts that enter the junction, distinguished by purple, are controlled by a button. This operation is only used for vehicles that are distinguished by a blue arrow. Carts that come along the road marked with a green arrow automatically travel to the warehouse. In this way, we can control the carts which are emptied when supplying the machining center and in a hectic situation, when the

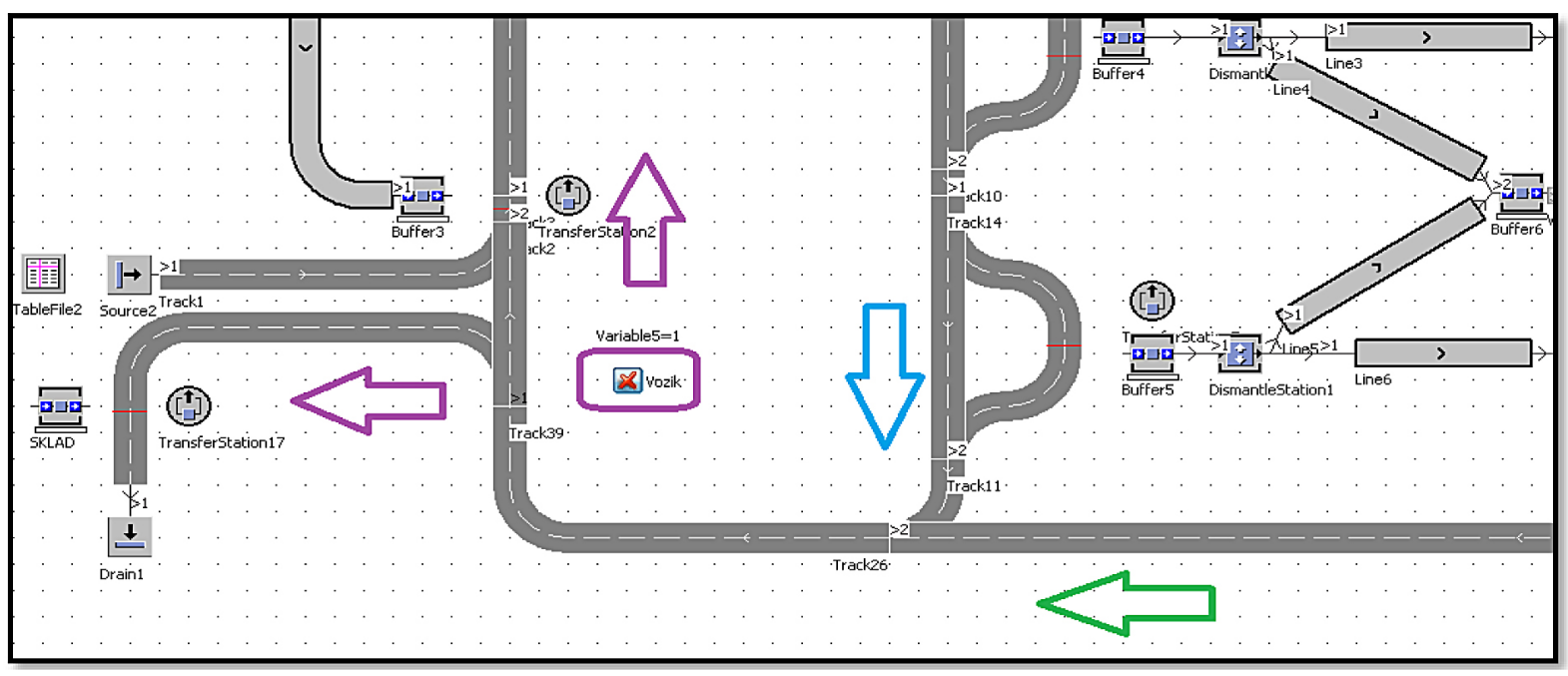

Fig. 7. Individual carts' direction 


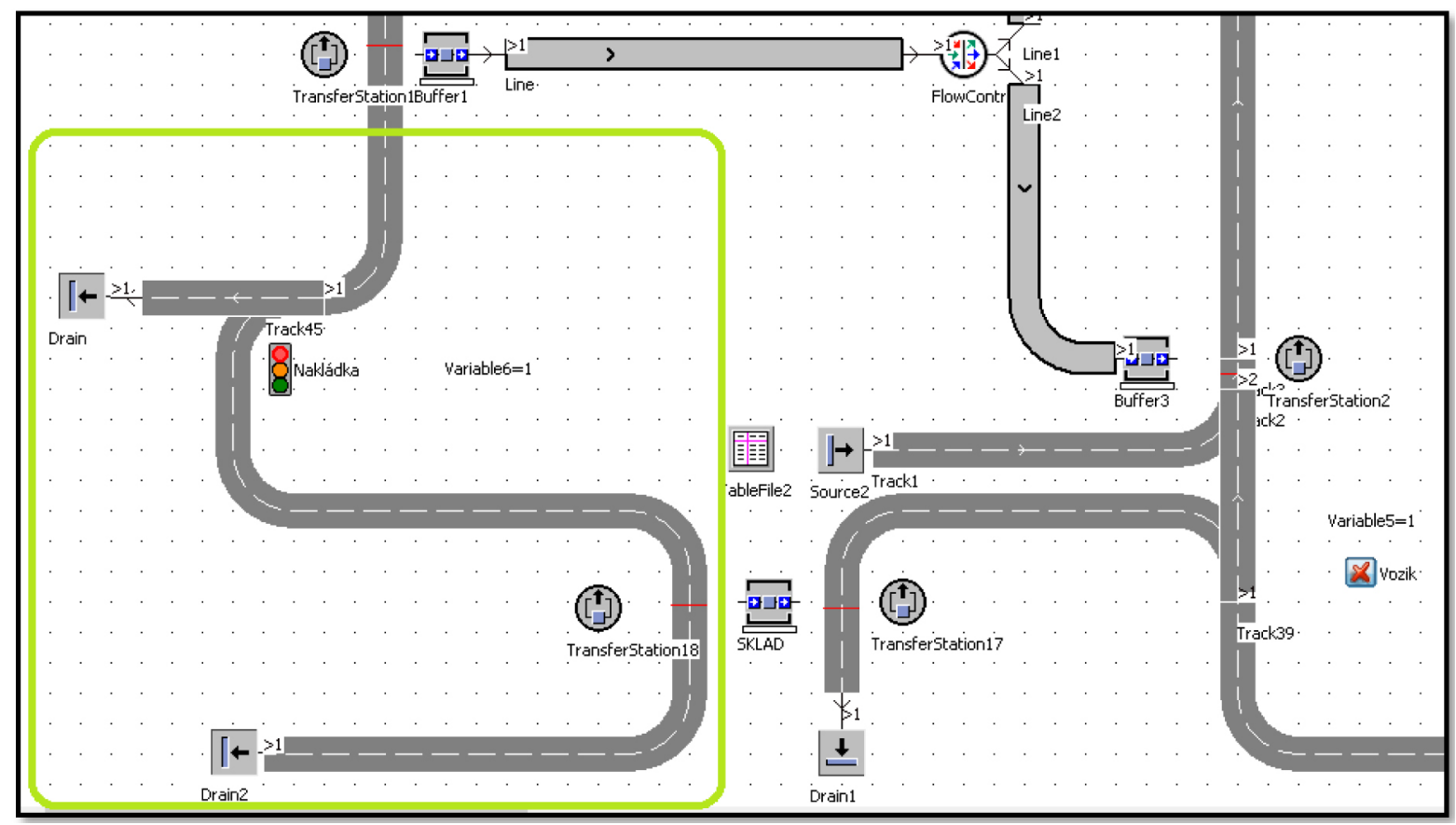

Fig. 8. Output area

magazines in the input area start to fill to the extreme, they provide extra help and transport the material back to the machining center.

Two types of carts enter the machining center. Therefore, the simulation language must cater to the situation where confirming the variable, e.g. by clicking on the button, returns these two types of vehicles to the input area. When the button is clicked, these carts will not return to the input area, but will move empty towards the output together with the handling units that have moved away from the assembly lines (Fig. 8). In contrast, the carts from the assembly lines need to be emptied so they can end their journey in the model.
The universal simulation model has a wide scope of application and has been created by applying various manufacturing operations that the software tool allows to use. It collects different types of information to analyze different activities. One of the possibilities is the application of the simulation model's verification capabilities within various changes in real operation and overall optimization of individual activities. This software tool can also be used to verify capacity in support of decision-making processes. Through the use of models, we can determine the required number of employees, possible reduction of employees, warehousing, expansion of production or even return on

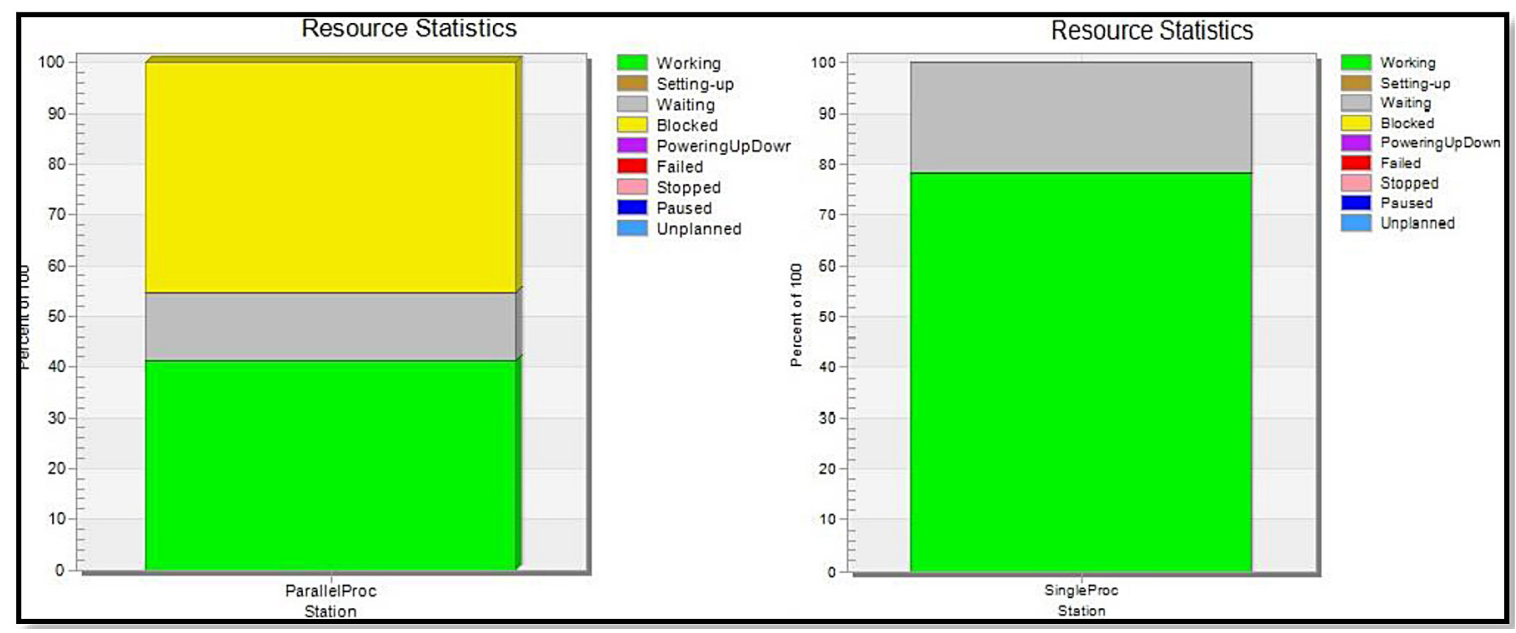

Fig. 9. Example of evaluation concerning activity at the individual workplaces 


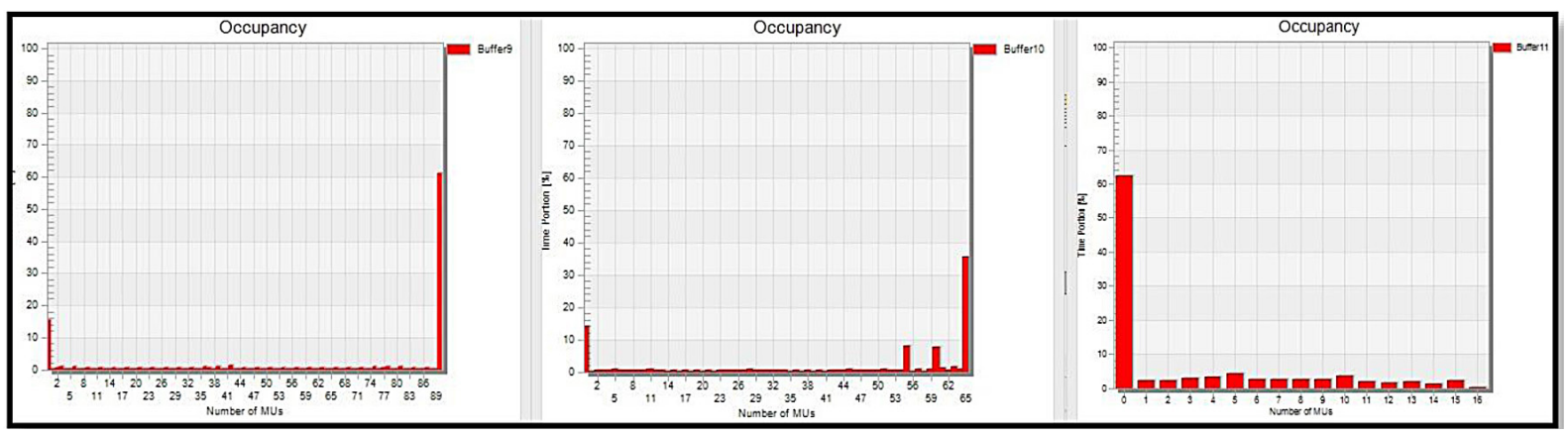

Fig. 10. Graph of workstations evaluation example

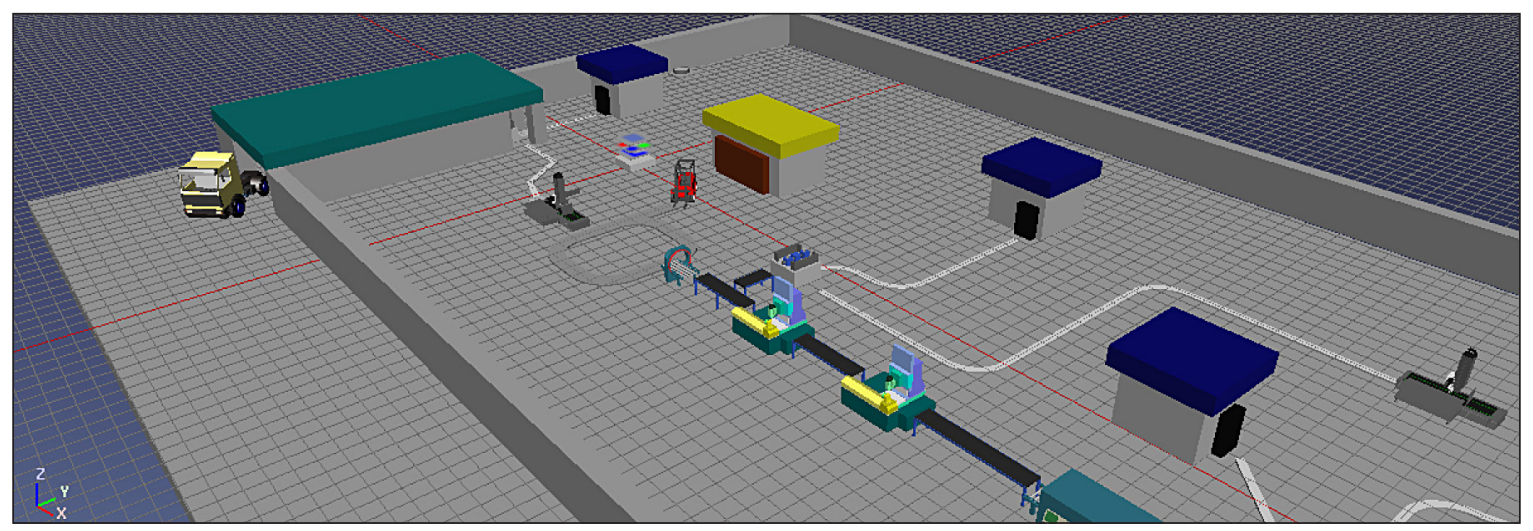

Fig. 11. 3D vizualizácia simulačného modelu

investment. Firms use such models to verify potential change without deployment of large financial resources, large simulation investments, and also to determine production efficiency.

The simulation model allows a detailed analysis of the supply chain and its individual links (Fig. 9). It enables evaluation of the supply level of individual workstations, allows for monitoring of stock and the size of individual supplies. At the same time, the simulation model makes it possible to visualize the individual links of the supply chain in a 3D preview.

\section{CONCLUSION}

Supply chains play one of the key roles in the logistics of production processes. Their functioning is influenced by various factors, which are often happen to be disruptions. It is often possible to come across opinions that where supply chains are concerned, critical situations result in udesirable conditions and threaten the chain. Yet even under the best organization, the emergence of disruptions cannot be avoided. They are a natural part of ongoing processes and cannot be completely eliminated.
In some cases, disruptions should not be necessarily looked at from a negative point of view. A critical situation may also be a motivation that can jumpstart the innovation process. Ultimately, the supply chain and its individual links can emerge from the crisis stronger, modernized. Its performance and operation may be improved. An example is the current pandemic situation, which has gravely impacted industries, the car industry including.

The adopted concept Industry 4.0, together with the adverse situation because of the coronavirus pandemic, which caused production problems by disruption of the material flows, shortages of manufacturing workers due to increased sickness absence and also due to border closures, paradoxically influenced and motivated the innovation of logistics processes.

The automotive industry is forced to deal with the situation and adopt measures in the form of introducing new technologies, developing digitization and automation. Active computer simulation tools can be used for this activity. Their role is to support the process of introducing new and progressive technologies aimed at increasing the quality of supply chain operations. Thus, disruptions need not be seen only as threats to supply chains, but also as an opportunity to improve them. 


\section{Acknowledgements}

This work is a part of these projects VEGA 1/0045/18, VEGA 1/0403/18, VEGA 1/0600/20, VEGA 1/0264/21, KEGA 012TUKE-4/2019, KEGA 013TUKE-4/2019.

\section{REFERENCES}

1. Cavinato JL. Supply chain logistics risks: From the back room to the board room. Int J Phys Distrib Logist Manag. 2004 Jan;34(5):383-7.

2. Faisal MN, Banwet DK, Shankar R. Supply chain risk mitigation: Modeling the enablers. Bus Process Manag J. 2006;12(4):535-52.

3. Midanek DH. When crisis crosses borders. MIT Sloan Manag Rev. 2004;45(1):16.

4. Natarajarathinam M, Capar I, Narayanan A. Managing supply chains in times of crisis: A review of literature and insights. Int $\mathrm{J}$ Phys Distrib Logist Manag. 2009;39(7):535-73.

5. Gros I. Vel'ká kniha logistiky. Praha, Česká republika: Vysoká škola chemicko-technologická v Praze; 2016. 507 p.

6. Van Der Vorst J, Beulens A, Van Beek P. Innovations in logistics and ICT in food supply chain networks. In: Innovation in Agri-Food Systems: Product Quality and Consumer. 2005. p. 245-90.

7. Mentzer JT, DeWitt W, Keebler JS, Min S, Nix NW, Smith CD, et al. Defining supply chain management. J Bus Logist. 2001;22(2):1-25.
8. Pour J, Gála L, Šedivá Z. Podniková informatika. Praha, Česká republika: Grada Publishing a.s.; 2006. 484 p.

9. Tarantilis CD, Kiranoudis CT, Theodorakopoulos ND. A Web-based ERP system for business services and supply chain management: Application to real-world process scheduling. Eur J Oper Res. 2008;187(3):1310-26.

10. Harrison A. Logistics Management and Strategy. Strateg Dir. 2007;23(3):10.

11. https://www.sciencedirect.com/topics/computerscience/supply-chain-council.

12. Kuechler W, Vaishnavi VK, Kuechler D. Supporting optimization of business-to-business e-commerce relationships. Decis Support Syst. 2001;31(3):363-77.

13. Hittle B, Leonard KM. Decision making in advance of a supply chain crisis. Manag Decis. 2011;49(7):1182-93.

14. Badea A, Prostean G, Goncalves G, Allaoui H. Assessing Risk Factors in Collaborative Supply Chain with the Analytic Hierarchy Process (AHP). Abrudan, I and Zimmermann, J and Nicolescu, $\mathrm{O}$ and Hulgard L, editor. Procedia - Soc Behav Sci. 2014;124:114-23.

15. Gurtu A, Johny J. Supply chain risk management: Literature review. Risks. 2021;9(1):1-16.

16. Ho W, Zheng T, Yildiz H, Talluri S. Supply chain risk management: A literature review William. Int J Prod Res. 2015;53(16):5031-69.

17. Armani AM, Hurt DE, Hwang D, McCarthy MC, Scholtz A. Low-tech solutions for the COVID-19 supply chain crisis. Nat Rev Mater. 2020;5(6):403-6.

18 . Tang CS. Perspectives in supply chain risk management. Int J Prod Econ. 2006;103(2):451-88. 